\title{
BMJ Open Increased utilisation of primary healthcare in persons exposed to severe stress in prenatal life: a national population-based study in Denmark
}

\author{
Jiong Li, ${ }^{1}$ Hu Yang, ${ }^{1,2}$ Mai-Britt Guldin, ${ }^{3}$ Peter Vedsted, ${ }^{3}$ Mogens Vestergaard ${ }^{3,4}$
}

To cite: Li J, Yang $\mathrm{H}$, Guldin M-B, et al. Increased utilisation of primary healthcare in persons exposed to severe stress in prenatal life: a national population-based study in Denmark. BMJ Open 2015;5: e005657. doi:10.1136/ bmjopen-2014-005657

- Prepublication history for this paper is available online. To view these files please visit the journal online (http://dx.doi.org/10.1136/ bmjopen-2014-005657).

Received 8 May 2014 Revised 29 November 2014 Accepted 22 December 2014

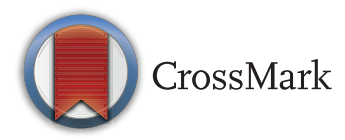

${ }^{1}$ Section for Epidemiology, Department of Public Health, Aarhus University, Aarhus, Denmark

${ }^{2}$ School of Information, Central University of Finance and Economics, Beijing, China

${ }^{3}$ Research Unit of General Practice, Department of Public Health, Aarhus University, Aarhus, Denmark ${ }^{4}$ Section for General Practice, Department of Public Health, Aarhus University, Aarhus, Denmark

\section{Correspondence to}

Jiong Li;

jl@soci.au.dk

\section{ABSTRACT}

Objective: Recent studies have suggested that stress in a pregnant mother may affect the future health of the unborn child negatively. An excellent proxy for health problems is the use of healthcare resources. Using nationwide data, we examined whether persons born to mothers who lost a close relative during pregnancy have more contacts to general practice.

Design: Population-based cohort study.

Setting: Denmark.

Participants: We included all children born in Denmark from 1973 to 2002 ( $N=2032$ 528). Exposure of prenatal stress was defined as maternal bereavement by the death of a close relative during the antenatal period. The outcome of interest was contact with general practice between 2003 and 2009 when the participants were between 1 and 35 years of age. Poisson regression was used to assess the association between exposure and outcome.

Outcome measures: Contacts to general practitioner. Results: Overall, persons exposed to prenatal stress had $2 \%$ more GP contacts than those not exposed, primarily due to increased utilisation of healthcare services during late adolescence and early adulthood. The exposed persons born to mothers who had lost a spouse had a higher risk (relative risk (RR) 1.12, 95\% Cl 1.10 to 1.14) and so did those born to mothers who had lost a close relative due to unexpected death (RR $1.06,95 \% \mathrm{Cl} 1.05$ to 1.06). Exposed persons had more contacts to general practice in daytime and more psychometric tests, talk therapies and $\mathrm{C}$ reactive protein tests than unexposed persons.

Conclusions: Prenatal stress following maternal bereavement was associated with a slightly increased utilisation of primary healthcare, mainly due to increased healthcare needs related to mental health and infections. Understanding how stress during pregnancy influences the future health of the child is an important aspect of prenatal care.

\section{INTRODUCTION}

A growing body of evidence suggests that exposure to environmental risk factors in fetal life plays a significant role in future

\section{Strengths and limitation of this study}

- This is the first large population-based cohort study to examine the association between prenatal stress and primary healthcare use, with virtually complete follow-up and no recall and selection bias. Furthermore, through linkage to other national registers, we were able to adjust for a number of potential confounders applying to both children and their mothers.

- The limitation of the study is that we have no data on changes in the mothers' glucocorticoid levels following bereavement, which is needed to examine dose-response patterns.

health. ${ }^{1}$ Major life events during pregnancy may cause stress reactions that affect the development of the unborn child ${ }^{23}$ and lead to ill health. Recent studies have shown that prenatal stress can be associated with more hospital admissions in the offspring later in life due to mental and physical disease. ${ }^{4} 5$ However, most diseases are diagnosed and treated in primary healthcare, which makes health service utilisation in general practice an important proxy for mental and physical health. Yet no studies have addressed how prenatal stress affects the utilisation of general practice services later in life.

Danish general practice provides taxfinanced comprehensive and continuous medical care to registered patients. ${ }^{6}$ A total of $99 \%$ of the Danish population is registered with a general practice. ${ }^{7}$ General practitioners (GPs) are freely accessible and serve as gatekeepers to the rest of the healthcare system. ${ }^{7}$ Except during emergencies, GPs are contacted if a person needs medical advice. In this way, studying Danish general practice can provide a detailed and complete description of a population's health status.

We used maternal bereavement during prenatal life as an indicator of prenatal stress as 
bereavement is likely to cause stress regardless of one's coping mechanisms. ${ }^{8}$ In a large population-based cohort study, we examined the associations between maternal bereavement during pregnancy and the offspring's use of primary healthcare up to 35 years of age. We expected that the association would be stronger if the mothers experienced bereavement due to sudden and unexpected causes of death rather than other causes of death. ${ }^{9}{ }^{10}$ We also expected that the death of another child in the family during pregnancy would affect the association more than the loss of a spouse or another relative. ${ }^{11}$

\section{METHODS}

\section{Study population, exposure and follow-up}

The unique personal identification number assigned to all citizens in Denmark permits accurate linkage of data between national registers, ${ }^{12}$ and this population-based cohort study was based on data from several national registers in Denmark: the CPR registry, the Medical Birth Register (MBR), the Integrated Database for Longitudinal Labour Market Research (IDA) and the Danish National Health Insurance Service Registry (NHSR). ${ }^{13}$ The cohort included all persons born in Denmark from 1973 to 2002 ( $\mathrm{N}=2032$ 528). Those who had emigrated or died before 2003 were excluded from the cohort $(\mathrm{N}=164977)$. We also excluded persons $(\mathrm{N}=47)$ who had visited their GP an unreasonable number of times in a year (more than 100 times). The final study population included 1867504 persons.

We categorised children as having been exposed to stress during prenatal life if their mothers had lost a child, a spouse, a sibling or a parent during their pregnancies or up to 1 year before conception (defined by gestational age). The remaining children were allocated to the unexposed cohort. Cohort members were followed from 1 January 2003 to 31 December 2009. To examine whether the associations were modified by type of experienced stress, we first categorised the exposed children into three groups based on maternal bereavement according to the mother's relation to the deceased relative: (1) loss of a spouse, (2) loss of a child and (3) loss of a parent or sibling. We further categorised the exposed children into two groups according to cause of death of the deceased relative: (1) unexpected/traumatic death including suicide and accidents (International Classification of Diseases Eighth Edition ICD-8 codes: 795, 810-823, 950-959, 800-807, 825-949, 960-999; ICD-10 codes: R95-R98,V01-V89,X60-X84) and (2) death by other causes.

\section{Outcome measurements}

We were interested in the overall use of general practice and specific procedures, in relation to mental and physical health. Danish general practice is fully computerised with computer-based patient records and submission of prescriptions digitally to pharmacies, etc. ${ }^{6}$ GPs are remunerated on a combination of capitation and fee-for-service $(25 / 75 \%)$. The GP therefore registers every specific contact and procedure in order to receive payment for services provided. The registration is collected electronically for administration in the National Health Services Register (NHSR) and is thus very complete and valid. ${ }^{6}$ Information on healthcare utilisation was obtained from the NHSR for exposed and unexposed persons. The NHSR provided data on consultations in daytime and out-of-hours $(\mathrm{OOH})$ and on diagnostic tests performed during the daytime. ${ }^{14}$

The main outcome of interest was the number of all GP visits per person year, the number of visits in daytime (time code ' 1 ') and the number of visits out of office hours (Time codes ' 8,9 '). We also studied face-to-face contacts alone (activity code 0101) and telephone consultations alone (activity code 0201). We also examined the reasons for contacts as we wanted to know whether prenatal stress led to differences in GP visits in types of treatment or management. For example, to measure activities related to physical health, we assessed taking a blood test (activity codes 2601, 2101), photometry test-B-haemoglobin (activity code 7108), CRP test (activity code 7120), spirometry/peakflow (activity codes 7113,7121,7183), ECG (7156) and urinary stix (activity code 7101). Measures of mental health activity were talk therapy/counselling (activity code 6101) and psychometric test (activity code 2149). Biological measurements (activity codes 2601, 2101, 7108, 7120, 7113, 7121, 7183, 7156, 7101) and psychometric activities (activity codes 6101,2149 ) were merged together into two separate groups. ${ }^{14}$

\section{Covariates}

Baseline characteristics were retrieved from registers in the child's birth year.

Perinatal factors (gestational age, birth weight, sibling order, Apgar score at $5 \mathrm{~min}$ ) were retrieved from the MBR. ${ }^{15}$ The MBR was established in 1968 and has been computerised since 1973. It holds data on all live births and stillbirths in Denmark, including characteristics of the mother and the newborn child, and variables with regard to pregnancy and delivery. Baseline sociodemographic factors were obtained from IDA, which contains longitudinal information on demographic variables and socioeconomic data from 1980 onwards. ${ }^{16}$

\section{Statistical analysis}

All data handling and statistical analyses were performed with the SAS V.9.2 statistical software package (SAS Institute, Inc, Cary, North Carolina, USA). Follow-up started from 2003 and ended in 2009.

We used Poisson regression model (SAS PROC PHREG procedure, V.9.1) to estimate relative ratios (RRs) with a 95\% CI to assess the association between prenatal bereavement and the risk of utilisation of general practice. The procedure of PROC MEANS was used to compute the total number of visits to general practice and the sum of person years for each patient. 
The procedure of PROC GENMOD was employed to estimate the RRs.

The following potential confounders were included in the analysis: calendar year (2003-2009), gender (male, female), age, gestational age $\left(0==^{\prime}>37\right.$ weeks', $1=$ 'less than 37 weeks'), Apgar score at $5 \mathrm{~min}(0-7,8-9,10$, unknown), parity $(1,2,3$, unknown), maternal age group ( $<27$ years, $27-30$ years, 31 years and over) and maternal education (0-9 years, $10-11$ years, $12+$ years $)$ and birthweight ( $1==^{\prime}$ less than 2500 g', $0==^{\prime}>2500$ g') .

\section{RESULTS}

The baseline characteristics of the cohorts are presented in table 1. Exposed children were more likely to have low birth weight, to be born preterm, to be second or later in birth order, or to be born to mothers having lower education. Fewer children born early in the study period were categorised as exposed because the registration of grandparents was incomplete. ${ }^{17}$
Table 2 shows that during follow-up, persons in the exposed group had $2 \%$ more contacts to general practice (Relative risk (RR) 1.02, 95\% CI 1.02 to 1.03 ) than persons in the unexposed group. Similar results were seen for face-to-face contact and telephone consultation. We found a stronger association between maternal bereavement and the offsprings RR of subsequent healthcare utilisation if the mother had lost a spouse (RR 1.12, 95\% CI 1.10 to 1.14) than if she had lost an older child (RR 1.05, 95\% CI 1.05 to 1.06). Persons of mothers who lost a close relative due to unexpected death had a higher healthcare utilisation (RR 1.06, 95\% CI 1.05 to 1.06) than persons of mothers who had lost a relative due to natural death (RR $1.01,95 \%$ CI 1.01 to 1.01; table 3).

The mean annual number of contacts to GPs was the same for exposed and unexposed persons during childhood, but exposed persons tended to have more contacts after reaching early adulthood (figure 1). The increase in GP service utilisation occurred during

Table 1 Baseline characteristics of the cohorts

\begin{tabular}{|c|c|c|c|c|}
\hline \multirow[b]{2}{*}{ Variables } & \multicolumn{2}{|l|}{ 1980-2002 } & \multicolumn{2}{|l|}{ 1973-2002 } \\
\hline & $\begin{array}{l}\text { Non-bereaved } \\
\mathrm{N}=1414287(97.30 \%)\end{array}$ & $\begin{array}{l}\text { Bereaved } \\
\mathrm{N}=38215(2.70 \%)\end{array}$ & $\begin{array}{l}\text { Non-bereaved } \\
\text { N=1 } 826806(97.826 \%)\end{array}$ & $\begin{array}{l}\text { Bereaved } \\
\mathrm{N}=40698(2.18 \%)\end{array}$ \\
\hline \multicolumn{5}{|l|}{ Gender } \\
\hline Male & $726671(51)$ & $19439(51)$ & $942715(52)$ & $20763(51)$ \\
\hline Female & $687614(49)$ & $18776(49)$ & $884089(48)$ & $19935(49)$ \\
\hline Missing & $2(0)$ & & $2(0)$ & \\
\hline \multicolumn{5}{|l|}{ Apgar score at $5 \mathrm{~min}$} \\
\hline 10 & 1264861 (89) & $36222(95)$ & $1366773(75)$ & $37201(91)$ \\
\hline $8-9$ & $32734(2)$ & $950(2)$ & $34774(2)$ & $985(2)$ \\
\hline $0-7$ & $7073(1)$ & $234(1)$ & $7371(0)$ & $238(1)$ \\
\hline Missing & 109619 (8) & $809(2)$ & $417888(23)$ & $2274(6)$ \\
\hline \multicolumn{5}{|l|}{ Birth Weight* } \\
\hline$\geq 2500 \mathrm{~g}$ & $1245876(88)$ & 35432 (93) & 1295492 (71) & $36006(88)$ \\
\hline$<2500 \mathrm{~g}$ & $64623(5)$ & $2133(6)$ & $67151(4)$ & $2180(5)$ \\
\hline Missing & $103788(7)$ & $650(2)$ & $464163(25)$ & $2512(6)$ \\
\hline \multicolumn{5}{|l|}{ Gestational age* } \\
\hline $0=37+$ weeks & $1222362(86)$ & $34990(92)$ & $1294836(71)$ & $35681(88)$ \\
\hline $1=$ less than 37 weeks & $70316(5)$ & $2303(6)$ & $73720(4)$ & $2359(6)$ \\
\hline Missing & 121609 (9) & $922(2)$ & $458250(25)$ & $2658(7)$ \\
\hline \multicolumn{5}{|l|}{ Parity } \\
\hline 1 & $645886(46)$ & $14321(37)$ & $956594(52)$ & $15024(37)$ \\
\hline 2 & $525185(37)$ & $15270(40)$ & $616084(34)$ & $16734(41)$ \\
\hline 3 & $234560(17)$ & 8621 (23) & $242170(13)$ & 8932 (22) \\
\hline Missing & $8656(1)$ & $3(0)$ & $11958(1)$ & $8(0)$ \\
\hline \multicolumn{5}{|l|}{ Maternal age, years } \\
\hline$<27$ & $495432(35)$ & 11267 (29) & 714820 (39) & $12682(31)$ \\
\hline $27-30$ & 439574 (31) & $11618(30)$ & $551663(30)$ & $12270(30)$ \\
\hline 31 and over & $473560(33)$ & $15330(40)$ & $553484(30)$ & 15746 (39) \\
\hline Missing & $5721(0)$ & & $6839(0)$ & \\
\hline \multicolumn{5}{|l|}{ Maternal education, years* } \\
\hline $0-9$ & $428202(30)$ & $12658(33)$ & $428202(23)$ & $12658(31)$ \\
\hline $10-11$ & 416669 (29) & 12351 (32) & 416669 (23) & $12351(30)$ \\
\hline $12+$ & $394823(28)$ & $11748(31)$ & $394823(22)$ & $11748(29)$ \\
\hline Missing & $174593(12)$ & $1458(4)$ & $587112(32)$ & $3941(10)$ \\
\hline
\end{tabular}


Table 2 Relative risk of any general practice visit by way of contact

\begin{tabular}{llccc}
\hline Exposure & Type of GP contact & Number of visits & Person years & Adjusted RR ${ }^{\star}$ (95\% Cl) \\
\hline Bereaved & All GP contacts & 1635761 & 280902 & $1.02(1.02$ to 1.02$)$ \\
& Contacts in office hours & 1453761 & 280902 & $1.02(1.02$ to 1.02$)$ \\
& Contacts out of hours & 181358 & 280902 & $1.03(1.02$ to 1.03$)$ \\
& Face-to-face contacts & 685094 & 280902 & $1.02(1.01$ to 1.02$)$ \\
Non-bereaved & Phone consultation & 451553 & 280902 & $1.02(1.02$ to 1.03$)$ \\
\hline
\end{tabular}

${ }^{*}$ Adjusted for age, calendar, sex, Apgar score at $5 \mathrm{~min}$, preterm birth, parity, low birth weight, maternal age and maternal education.

GP, general practitioner.

daytime but not during OOHs. From adolescence and early adulthood, psychometric tests and counselling were more frequent in the exposed group than in the non-exposed group. In the same age groups, the use of biological examinations (including blood tests, CRP tests) was also higher among the exposed than among the unexposed persons (figure 2).

\section{DISCUSSION}

We are the first to observe that prenatal stress following maternal bereavement is associated with a slightly higher use of primary healthcare in the offspring during late adolescence and early adulthood. The association was stronger if the mother lost her spouse than if she lost another relative. Sudden death of mothers' relatives was associated with a higher risk than other causes of death. An excess number of visits was found for mental health problems (talk-therapies, psychometric tests) and for physical tests (blood tests, ECGs, CRP tests).

A large body of literature has concluded that bereavement is one of the most stressful life events and that it affects most people regardless of their coping mechanisms. ${ }^{18} 19$ The use of bereavement as an indicator of stress

Table 3 Relative risk (RR) of any general practice visit according to type of loss (bereavement)

\begin{tabular}{|c|c|c|c|c|}
\hline Type of loss & Type of GP contact & Number of Visits & Person years & Adjusted $\mathbf{R R}^{\star}(95 \% \mathrm{Cl})$ \\
\hline Non-bereaved & All contacts & 78178124 & 12465586 & 1.00 (ref) \\
\hline \multicolumn{5}{|c|}{ Bereaved-relationship to the deceased relative } \\
\hline Sibling & All contacts & 338235 & 50630 & 1.06 (1.06 to 1.07$)$ \\
\hline Father & All contacts & 28164 & 3752 & $1.12(1.11$ to 1.14$)$ \\
\hline Other & All contacts & 1269362 & 226520 & $1.01(1.00$ to 1.01$)$ \\
\hline Sibling & Contacts in office hours & 303921 & 50630 & $1.05(1.05$ to 1.06$)$ \\
\hline Father & Contacts in office hours & 25271 & 3752 & $1.12(1.10$ to 1.14$)$ \\
\hline Other & Contacts in office hours & 1124569 & 226520 & $1.00(1.00$ to 1.01$)$ \\
\hline Sibling & Contacts out-of-hours & 34219 & 50630 & 1.15 (1.13 to 1.16$)$ \\
\hline Father & Contacts out-of-hours & 2889 & 3752 & $1.18(1.13$ to 1.24$)$ \\
\hline Other & Contacts out-of-hours & 144250 & 226520 & 1.02 (1.01 to 1.03$)$ \\
\hline Sibling & Face-to-face contacts & 137561 & 50630 & 1.07 (1.06 to 1.07$)$ \\
\hline Father & Face-to-face contacts & 11572 & 3752 & $1.13(1.10$ to 1.15$)$ \\
\hline Other & Face-to-face contacts & 535961 & 226520 & 1.00 (1.00 to 1.00$)$ \\
\hline Sibling & Phone consultation & 95612 & 50630 & $1.10(1.09$ to 1.11$)$ \\
\hline Father & Phone consultation & 8019 & 3752 & 1.13 (1.09 to 1.16$)$ \\
\hline Other & Phone consultation & 347922 & 226520 & 1.01 (1.01 to 1.02$)$ \\
\hline \multicolumn{5}{|c|}{ Bereaved-type of death $\dagger$} \\
\hline Sudden death & All contacts & 262489 & 42011 & 1.06 (1.05 to 1.06$)$ \\
\hline Other deaths & All contacts & 1353226 & 235373 & 1.01 (1.01 to 1.01$)$ \\
\hline Sudden death & Contacts in office hours & 233219 & 42011 & 1.05 (1.05 to 1.06$)$ \\
\hline Other deaths & Contacts in office hours & 1202551 & 235373 & $1.01(1.00$ to 1.01$)$ \\
\hline Sudden death & Contacts out-of-hours & 42011 & 42011 & $1.11(1.10$ to 1.13$)$ \\
\hline Other deaths & Contacts out-of-hours & 150121 & 235373 & 1.03 (1.02 to 1.03$)$ \\
\hline Sudden death & Face-to-face contacts & 109286 & 42011 & 1.05 (1.04 to 1.06$)$ \\
\hline Other deaths & Face-to-face contacts & 567144 & 235373 & $1.00(1.00$ to 1.01$)$ \\
\hline Sudden death & Phone consultation & 73049 & 42011 & 1.08 (1.07 to 1.09$)$ \\
\hline Other deaths & Phone consultation & 373081 & 235373 & 1.02 (1.01 to 1.02$)$ \\
\hline
\end{tabular}

${ }^{*}$ Adjusted for age, calendar, sex, Apgar scores at 5 min, preterm birth, parity, low birth weight, maternal age and maternal education. †Sudden death: unexpected/traumatic death, mostly from suicide and accidents. GP, general practitioner. 

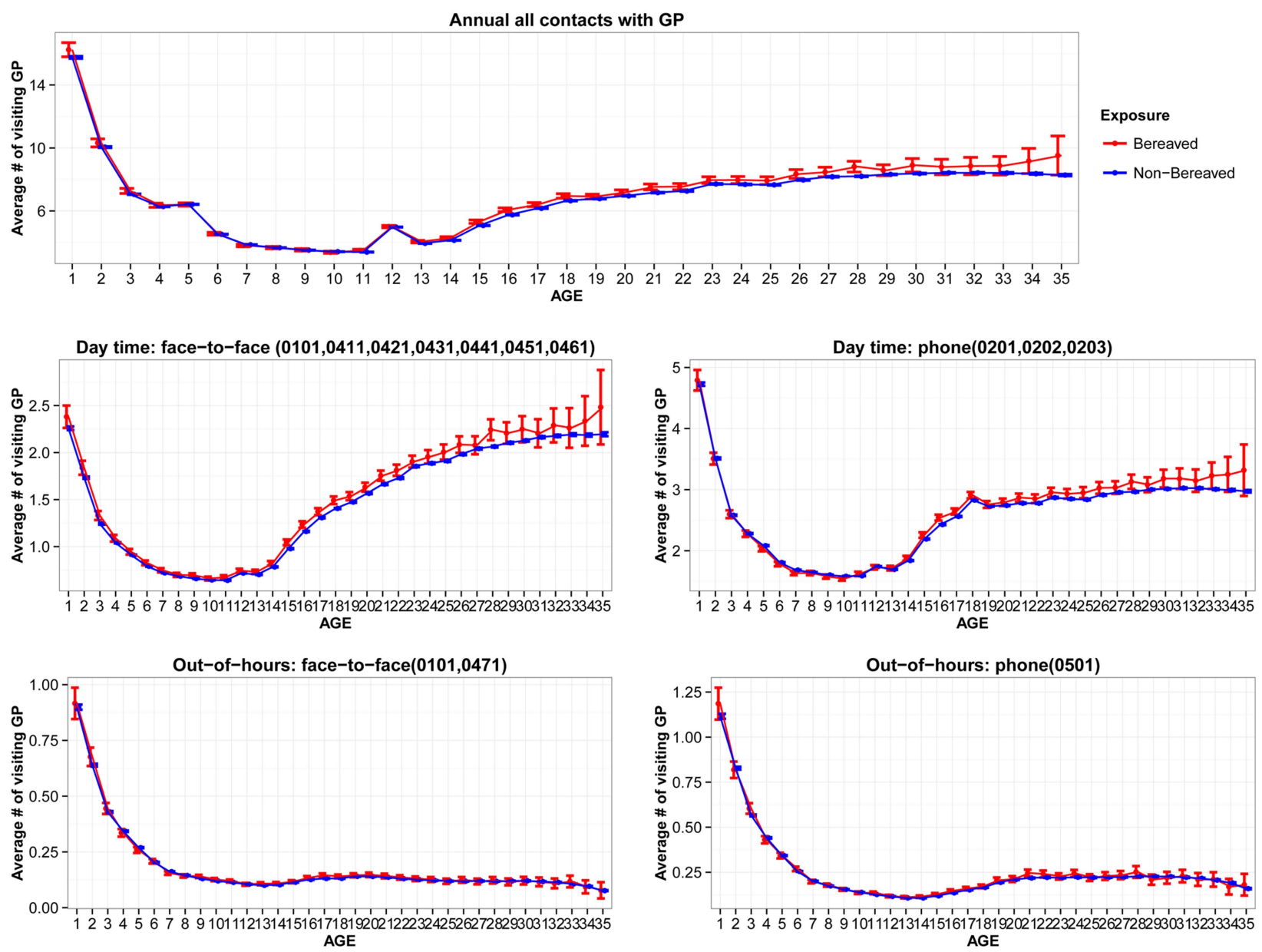

Figure 1 Contacts with general practitioner, by type of contact and time of contact.

in research therefore seems justified as it provides a good exposure contrast between exposed and unexposed. We collected information on bereavement prospectively without relying on the participants' memory. The registration of the day of death is known to be of very high quality in Danish nationwide registries, and our data on bereavement from the Danish Civil Registration System are therefore valid and complete (close to $100 \%$ ). This yields accurate information on the exposure in focus. ${ }^{17}$ The unique nature of the Danish national register data provides our study with a number of other important methodological strengths. For example, the study was based on a large population-based cohort of all children born in Denmark, and follow-up during the period 2003-2009 was virtually complete. ${ }^{17}$ Bias due to selection of study participants and non-response is therefore an unlikely explanation of our findings. Furthermore, through linkage to other national registers, we were able to adjust for a number of potential confounders applying to children as well as to their mothers.

One limitation of the study is that we have no data on changes in the mothers' glucocorticoid levels following bereavement, which is needed to examine dose-response patterns. Yet, it is hardly realistic to have a biological measurement in such a large study population. Furthermore, we have no data on lifestyle factors that could confound the associations. However, the sociodemographic factors included in the model will, to some extent, adjust for the effects of lifestyle factors. Another limitation is the heterogeneity of the data on GP contacts and the inclusion of contacts from all causes, which may prevent us from examining the associations between prenatal stress and specific diseases or health problems. However, this was not defined as the main interest of this study.

The findings support our hypothesis of a possible dose-response association between cause of death and stress level. Previous studies have also shown that unexpected deaths are more stressful than expected deaths, ${ }^{10}$ and that the loss of a relative in the nuclear family is more stressful than the loss of another relative. ${ }^{11}$

To the best of our knowledge, this is the first population-based study to examine how prenatal stress is associated with health service use in later life. Previous research of health outcomes has focused on birth outcomes, hospital diagnoses related to physical diseases, ${ }^{4}$ psychiatric disorders ${ }^{5} 20$ and social/emotional problems. ${ }^{21} 22$ Our findings of increased healthcare utilisation support the hypothesis of prenatal stress programming, ${ }^{2}{ }^{3}{ }^{23}$ albeit from a new point of view. Prenatal stress programming refers to the underlying 

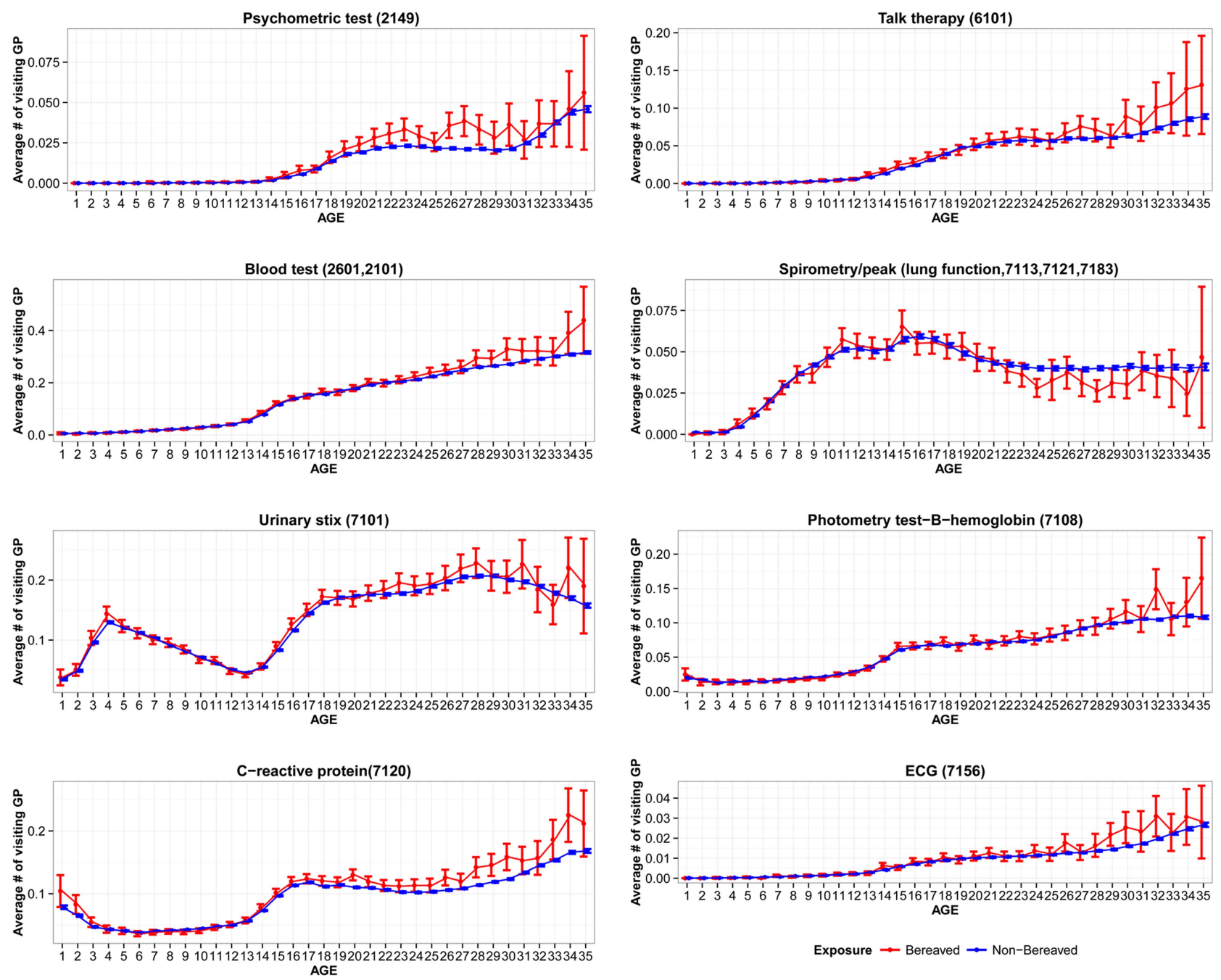

Figure 2 Contacts with general practitioner, by reasons of contact.

biological mechanisms that result from the disruption of the normal pattern of fetal development by an abnormal stimulus or insult at a critical time point. ${ }^{24}{ }^{25}$ Excessive glucocorticoid levels following stress in pregnant mothers can cause dysfunction of the hypothalamopituitaryadrenocortical (HPA) axis with permanent effects on the development of a number of body systems in the fetus, ${ }^{2425}$ which may lead to adverse health outcomes in future life. Strong evidence from animal studies suggests that maternal stress during pregnancy may significantly affect the neurodevelopment of the fetus. These animal studies have recently been followed by a number of studies in human populations. ${ }^{5} 2627$ Confirming these studies, our findings showed more frequent visits for psychometric tests and counselling in exposed than in unexposed persons, particularly from early adulthood onwards. Our findings of a higher number of blood tests in general practice among exposed than among unexposed persons may lend support to the argument that prenatal stress might be linked to metabolic syndrome, obesity risk or cardiovascular diseases. ${ }^{28-30}$ Lastly, the more frequent testing of CRP in exposed than in unexposed persons is also in line with observations in animal studies that prenatal stress affects immune function development, ${ }^{31}$ and in one recent human study that prenatal stress was associated with more hospitalisations due to severe infectious diseases. ${ }^{32}$

Another interesting finding to be mentioned is the higher risks related to the death of a spouse than another older child during pregnancy. Little is known about the effects of spousal loss in pregnancy on the mother herself or on the offspring, probably because it is a very rare event and because it is very challenging to obtain data on this relationship. One recent study has shown that loss of a spouse during pregnancy is related to substance abuse in the offspring. ${ }^{33}$ Our study suggests that the loss of a father during prenatal life may have more severe consequences than the loss of other family members on future health. The underlying reasons for this association is unclear, but the loss of a father may affect the child's upbringing, socioeconomic surroundings, parental resources and the threshold for attending healthcare. ${ }^{34} 35$

It might not be of very clinical significance, as we only observed a mildly increased utilisation in health service 
use following this specific event of bereavement. However, it should be noted that bereavement during pregnancy is only one of many stressful life events and that it accounts for only a small fraction of the overall stress level in pregnant mothers. Many other stressful events could affect women in pregnancy and cause stress in the unexposed group as well, and an increase in health service use in later life following prenatal stress may therefore be anticipated due to other causes. It is therefore important to recognise the potential effects of stress at the first step. How the combined maternal psychological stress affects future health service use is warranted to be investigated in future studies. On the other hand, it remains to be elucidated whether the associations are different for specific stress exposures, depending on the treatment and specific disease outcomes.

In conclusion, offspring exposed to prenatal stress utilised general practice more than unexposed offspring, but only in later adolescence and early adulthood. Our findings contribute to our understanding of the aetiology of stress-related ill health from the view of disease programming. Severe stress during prenatal life may programme future health in future life, which highlights the importance of better care in women's health during pregnancy. $^{2} 323$ This information should be taken into account when implementing preventive programmes in maternal and child health.

Contributors $\mathrm{JL}$ conceived the research and wrote the first draft of the manuscript. JL, HY, M-BG, PV and MV contributed to data analysis, interpretation of results and critical revision of the manuscript. HY analysed the data. All authors approved the final manuscript.

Funding This work is supported by a grant from the European Research Council (ERC-StG-2010-260242-PROGEURO), part of the European Union Seventh Framework for Research; and the Nordic Cancer Union (2013-129830); the NordForsk (070331); the Danish Medical Research Council (09-072986); and an unrestricted grant from the Lundbeck foundation (MEPRICA).

Competing interests None.

Ethics approval The study was approved by Danish Data Protection Agency (j nr 2008-41-2680), Scientific Ethics Committee of Central Region Jylland (VEK, sag nr M-20100252).

Provenance and peer review Not commissioned; externally peer reviewed.

Data sharing statement No additional data are available.

Open Access This is an Open Access article distributed in accordance with the Creative Commons Attribution Non Commercial (CC BY-NC 4.0) license, which permits others to distribute, remix, adapt, build upon this work noncommercially, and license their derivative works on different terms, provided the original work is properly cited and the use is non-commercial. See: http:// creativecommons.org/licenses/by-nc/4.0/

\section{REFERENCES}

1. Gluckman PD, Hanson MA, Cooper C, et al. Effect of in utero and early-life conditions on adult health and disease. New Engl J Med 2008;359:61-73.

2. Kapoor A, Dunn E, Kostaki A, et al. Fetal programming of hypothalamo-pituitary-adrenal function: prenatal stress and glucocorticoids. J Physiol (Lond) 2006;572:31-44.

3. Markham JA, Koenig JI. Prenatal stress: role in psychotic and depressive diseases. Psychopharmacology (Berl) 2011;214:89-106.

4. Hansen D, Lou HC, Olsen J. Serious life events and congenital malformations: a national study with complete follow-up. Lancet 2000;356:875-80.
5. Khashan AS, Abel KM, McNamee R, et al. Higher risk of offspring schizophrenia following antenatal maternal exposure to severe adverse life events. Arch Gen Psychiatry 2008;65:146-52.

6. Pedersen KM, Andersen JS, Soendergaard J. General practice and primary health care in Denmark. J Am Board Fam Med 2012;25:S34-8.

7. Christiansen T. Organization and financing of the Danish health care system. Health Policy 2002;59:107-18.

8. Stroebe M, Schut H, Stroebe W. Health outcomes of bereavement. Lancet 2007;370:1960-73.

9. Kristensen P, Weisæth L, Heir T. Bereavement and mental health after sudden and violent losses: a review. Psychiatry 2012;75:76-97.

10. Li J, Precht DH, Mortensen PB, et al. Mortality in parents after death of a child in Denmark: a nationwide follow-up study. Lancet 2003;361:363-7.

11. Skodol AE, Shrout PE. Use of DSM-III axis IV in clinical practice: rating etiologically significant stressors. Am J Psychiatry 1989;146:61-6.

12. Frank L. Epidemiology. When an entire country is a cohort. Science 2000;287:2398-9.

13. Li J, Vestergaard M, Obel C, et al. Cohort profile: the Nordic perinatal bereavement cohort. Int J Epidemiol 2010;40:1161-7.

14. Olivarius NF, Hollnagel $\mathrm{H}$, Krasnik $A$, et al. The Danish National Health Service Register. A tool for primary health care research. Dan Med Bull 1997;44:449-53.

15. Knudsen LB, Olsen J. The Danish Medical Birth Registry. Dan Med Bull 1998;45:320-3.

16. Denmark Statistics. IDA-an intergrated database for labor market research. (In Danish). (under IDA (Intergrated Database for Arbejdsmarkedsforskning)). 1991. (http://www.dst.dk/).

17. Pedersen CB, Gotzsche H, Moller JO, et al. The Danish Civil Registration System. A cohort of eight million persons. Dan Med Bull 2006;53:441-9.

18. Holmes $\mathrm{TH}$, Rahe RH. The Social Readjustment Rating Scale. J Psychosom Res 1967;11:213-8.

19. Osterweis M, Solomon F, Green M. Bereavement: reactions, consequences, and care. Washington, DC: National Academy Press, 1984.

20. Huttunen MO, Niskanen P. Prenatal loss of father and psychiatric disorders. Arch Gen Psychiatry 1978;35:429-31.

21. Van den Bergh BR, Mulder EJ, Mennes M, et al. Antenatal maternal anxiety and stress and the neurobehavioural development of the fetus and child: links and possible mechanisms. A review. Neurosci Biobehav Rev 2005;29:237-58.

22. O'Connor TG, Heron J, Golding J, et al. Maternal antenatal anxiety and behavioural/emotional problems in children: a test of a programming hypothesis. J Child Psychol Psychiatry 2003;44:1025-36.

23. Weinstock $M$. The potential influence of maternal stress hormones on development and mental health of the offspring. Brain Behav Immun 2005;19:296-308.

24. Viltart O, Vanbesien-Mailliot CC. Impact of prenatal stress on neuroendocrine programming. Sci World J 2007;7:1493-537.

25. Welberg LA, Seckl JR. Prenatal stress, glucocorticoids and the programming of the brain. J Neuroendocrinol 2001;13:113-28.

26. Abel KM, Heuvelman HP, Jorgensen L, et al. Severe bereavement stress during the prenatal and childhood periods and risk of psychosis in later life: population based cohort study. BMJ 2014;348:f7679.

27. Li J, Vestergaard M, Obel C, et al. A nationwide study on the risk of autism after prenatal stress exposure to maternal bereavement. Pediatrics 2009;123:1102-7.

28. Reynolds RM. Corticosteroid-mediated programming and the pathogenesis of obesity and diabetes. J Steroid Biochem Mol Biol 2010;122:3-9.

29. Reynolds RM. Glucocorticoid excess and the developmental origins of disease: two decades of testing the hypothesis-2012 Curt Richter Award Winner. Psychoneuroendocrinology 2013;38:1-11.

30. Entringer S, Buss C, Wadhwa PD. Prenatal stress and developmental programming of human health and disease risk: concepts and integration of empirical findings. Curr Opin Endocrinol Diabetes Obes 2010;17:507-16.

31. Parker VJ, Menzies JRW, Douglas AJ. Differential changes in the hypothalamic-pituitary-adrenal axis and prolactin responses to stress in early pregnant mice. J Neuroendocrinol 2011;23:1066-78.

32. Nielsen NM, Hansen AV, Simonsen J, et al. Prenatal stress and risk of infectious diseases in offspring. Am J Epidemiol 2011;173:990-7.

33. Liang $\mathrm{H}$, Olsen J, Cnattingus $\mathrm{S}$, et al. Risk of substance use disorders following prenatal or postnatal exposure to bereavement. Drug Alcohol Depend 2013;132:277-82.

34. East L, Jackson D, O'Brien L. Father absence and adolescent development: a review of the literature. J Child Health Care 2006;10:283-95.

35. McLanahan S, Tach L, Schneider D. The causal effects of father absence. Annu Rev Sociol 2013;399:399-427. 